\title{
PAPILLON-LEFEVRE SYNDROME: A CASE REPORT
}

\author{
P. Guru Prasad ${ }^{1}$, P. V. Sudhakar², R. Rama ${ }^{3}$, P. V. S. V. P. H. S. Brahma ${ }^{4}$, Padmasree Somala Y5
}

\section{HOW TO CITE THIS ARTICLE:}

P. Guru Prasad, P. V. Sudhakar, R. Rama, P. V. S. V. P. H. S. Brahma, Padmasree Somala Y. "Papillon-Lefevre Syndrome: A Case Report". Journal of Evolution of Medical and Dental Sciences 2015; Vol. 4, Issue 05, January 15; Page: 894-898, DOI: 10.14260/jemds/2015/128

ABSTRACT: Papillon-Lefèvre syndrome (PLS) is a very rare syndrome of autosomal recessive inheritance characterized by progressive palmar-plantar keratoderma and early onset periodontitis, leading to premature loss of both primary and permanent dentitions and recurrent pyogenic infections. Patient Presented with a chief complaint of thickening of palms and soles extending on to knees and elbows.. On intraoral examination there is loss of both temporary and permanent teeth. Patient had recurrent pyogenic infections involving face and nose leading to nasal destruction. Histopathological examination of the specimen taken from the thickened skin was reported to be consistent with PLS $1,2,3$

KEYWORDS: Palmar plantar keratoderma, periodontitis, recurrent pyogenic infections.

INTRODUCTION: The Papillon-Lefèvre syndrome (PLS) was first described by Papillon and Lefèvre in 1924.[4] PLS is an autosomal recessive disorder that is caused by mutations in cathepsin C (CTSC). PLS is characterized by palmoplantar keratoderma and aggressive periodontitis. It has world-wide prevalence of 1-4 cases per million in the general population and is often related with consanguinity.[1,4,5]

CASE REPORTS: A 18-year-old male patient to the skin OPD with the chief complaint markedly thickening of palms and soles, with scaly erythematous lesions over knees and elbows and loss of teeth and scars. Over face and deformity of nasal ala on left side.1,2,6,7

On examination patient had progressive palmoplantar keratoderma, loss of both temporary and permanent teeth, recurrent infections predominantly involving forehead and nose. palmoplantar keratoderma present at birth. ${ }^{8}$ keratoderma involves palms, soles, back, heel, external malleolus, tibial tuberosities, elbows and dorsae of hands and feet.

Hair and nails are normal.

On intraoral examination there had been early shedding of deciduous teeth which erupted normally and complete shedding of all deciduous teeth by the age of $6 \mathrm{yrs}^{4,5}$. There has been normal eruption of permanent teeth but gradually his teeth has started becoming mobile and this was followed by loss of all permanent teeth except 3 molars which are also mobile. Gingival recession was present in all teeth.

In addition patient gave history of recurrent pustular lesions involving the forehead, left side of nose leading to scaring over the forehead and nasal deformity on left side of nose. ${ }^{9}$

All investigations are with in normal limits, x-ray of skull normal, mantoux test is normal.

Histopathology from thick plaque is suggestive of keratoderma. Biopsy from nasal ala ruled out any evidence of tuberculosis. Assistance of Plastic Surgeon was taken for reconstruction of nose. 


\section{CASE REPORT}

DISCUSSION: Papillon lefevre syndrome is a disorder of keratinisation that is inherited in a AR pattern It is characterized by progressive palmoplantar keratoderma, periodontitis, 50 and recurrent pyogenic infections. Onset of symptoms is between 1 and 4 years of age in our case skin and periodontal findings correlate with previous case reports. . $^{1,2,3}$

Dental history was also in accordance with previous case reports.4,5 In addition to dermatological and oral findings patient had recurrent pyogenic infection leading to scarring over forehead and deformity of nose requiring plastic surgeon assistance for nasal reconstuction.

Recurrent pyogenic infection leading to nasal destruction has not been reported. This in contrast with case reports, which reported recurrent infections without any sequale. This can be attributed to decreased neutrophil, lymphocyte and monocyte functions, that predispose to recurrent pyogenic infections.

CTSC gene mutations have been reported as responsible for PLS, CTSC deficiency has been associated with PLS-associated increased susceptibility to bacterial infection in gums and other sites. ${ }^{11}$

MANAGEMENT: He was kept on Oral isotretinoin $20 \mathrm{mg}$ od palmo plantar keratoderma improved gradually ${ }^{12,13}$ Oral antibiotics were given to treat recurrent pyogenic infections.

Plastic Surgical reconstruction of deformed nose: Nasolabial flap was used to reconstruct the lost ala nasi to improve the appearance of the grotesque shape of the nose. The outcome after surgery was quite satisfactory. Prosthetic rehabilitation with removable partial dentures.

CONCLUSION: It is important that dermatologists should be familiar with PLS, for early diagnosis of PLS. Associated periodontitis and institution of an appropriate periodontal/antimicrobial treatment.

\section{REFERENCES:}

1. Janjua SA, Khachemoune A. Papillon-Lefevre syndrome: Case report and review of the literature. Dermatol Online J 2004; 10: 13.

2. Rathi SK. Papillon-Lefevre Syndrome in two brothers. Indian J Dermatol Venerol Leprol 2002; 68: 155-6.

3. Gonzalez JR, Chabrier L, Rodriguez RJ. Papillion Lefevre syndrome: A case report and review of literature. PR Health Science J 1997; 16: 279-81.

4. Papillon MM, Lefèvre P. Two cases of symmetrical, familial (Meleda's malady) palmar and plantar keratosis of brother and sister: Coexistence in two cases with serious dental changes. Bull Soc Fr Dermatol Syphiligr. 1924; 31: 82-7.

5. Hart TC, Shapira L. Papillon-Lefèvre syndrome. Periodontol 2000. 1994; 6: 88-100. [PubMed]

6. Mahajan VK, Thakur NS, Sharma NL. Papillon-Lefevre syndrome. Indian Pediatr 2003; 40: 1197200.

7. Yagmur A, Yilmaz G, Ertan U, IKizoglu E, Ozkasap S, Karacan C. Papillon Lefevre syndrome: A case report. Int Pediatr 2004; 19: 224-5.

8. Galanter DR, Bradford S. Case report. Hyperkeratosis palmoplantaris and periodontosis: The Papillon-Lefevre Syndrome. J Periodontol 1969; 1: 40-7.

9. Khandpur S, Reddy BS. Papillon-Lefèvre syndrome with pyogenic hepatic abscess: A rare association.Pediatr Dermatol. 2001; 18: 45-7. [PubMed].

10. Gorlin RJ. Of palms, soles, and gums. J Med Genet. 2000; 37: 81-2. [PMC free article] [PubMed] 


\section{CASE REPORT}

11. Cury VF, Costa JE, Gomez RS, Boson WL, Loures CG, De ML. A novel mutation of the cathepsin C gene in Papillon-Lefèvre syndrome. J Periodontol. 2002; 73: 307-12. [PubMed]

12. AI-Khenaizan S.Papillon-Lefivre syndrome: The response to acitretin. Int J Dermatol 2002; 41 : 638-41.

13. Tosti A, Manuzzi P, Bardazzi F, Costa A. Is etretinate dangerous in Papillon-Lefèvre syndrome? Dermatologica. 1988; 176: 148-50. [PubMed].

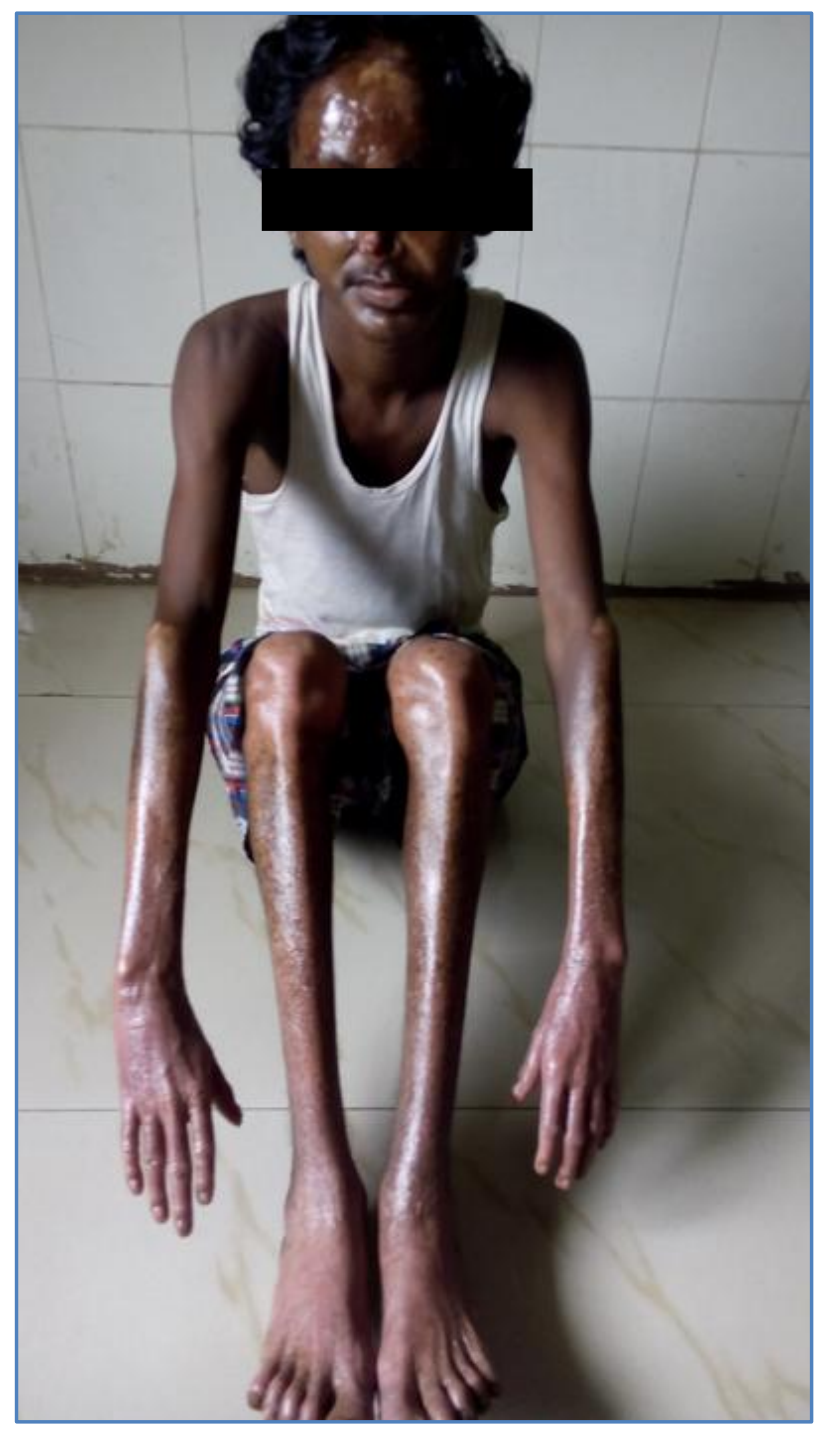

keratoderma involves palms, soles, back,heel, external malleolus, tibial tuberosities,elbows and dorsae of hands and feet 


\section{CASE REPORT}

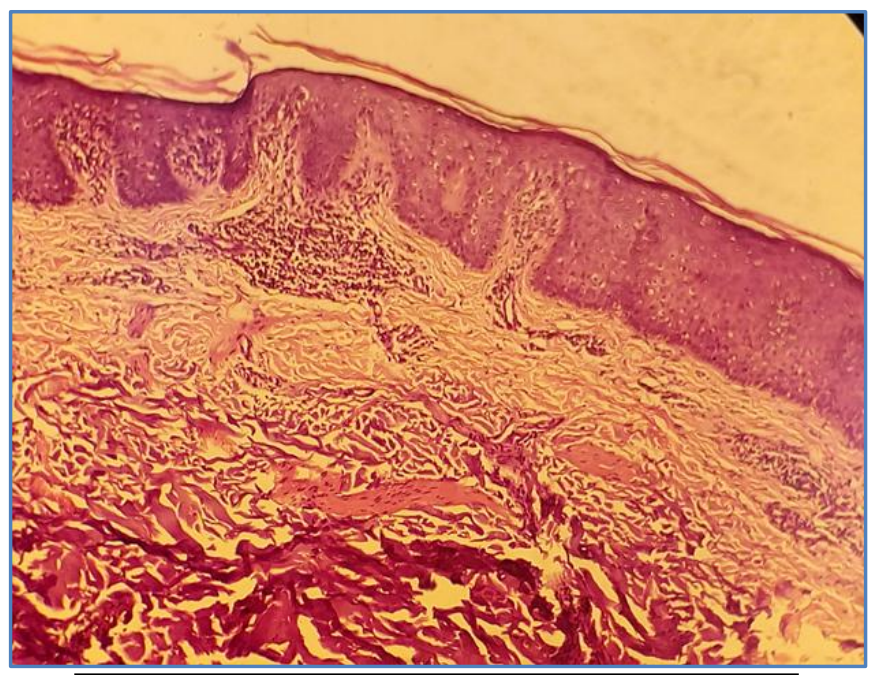

\section{Skin biopsy: Psoriasiform features}
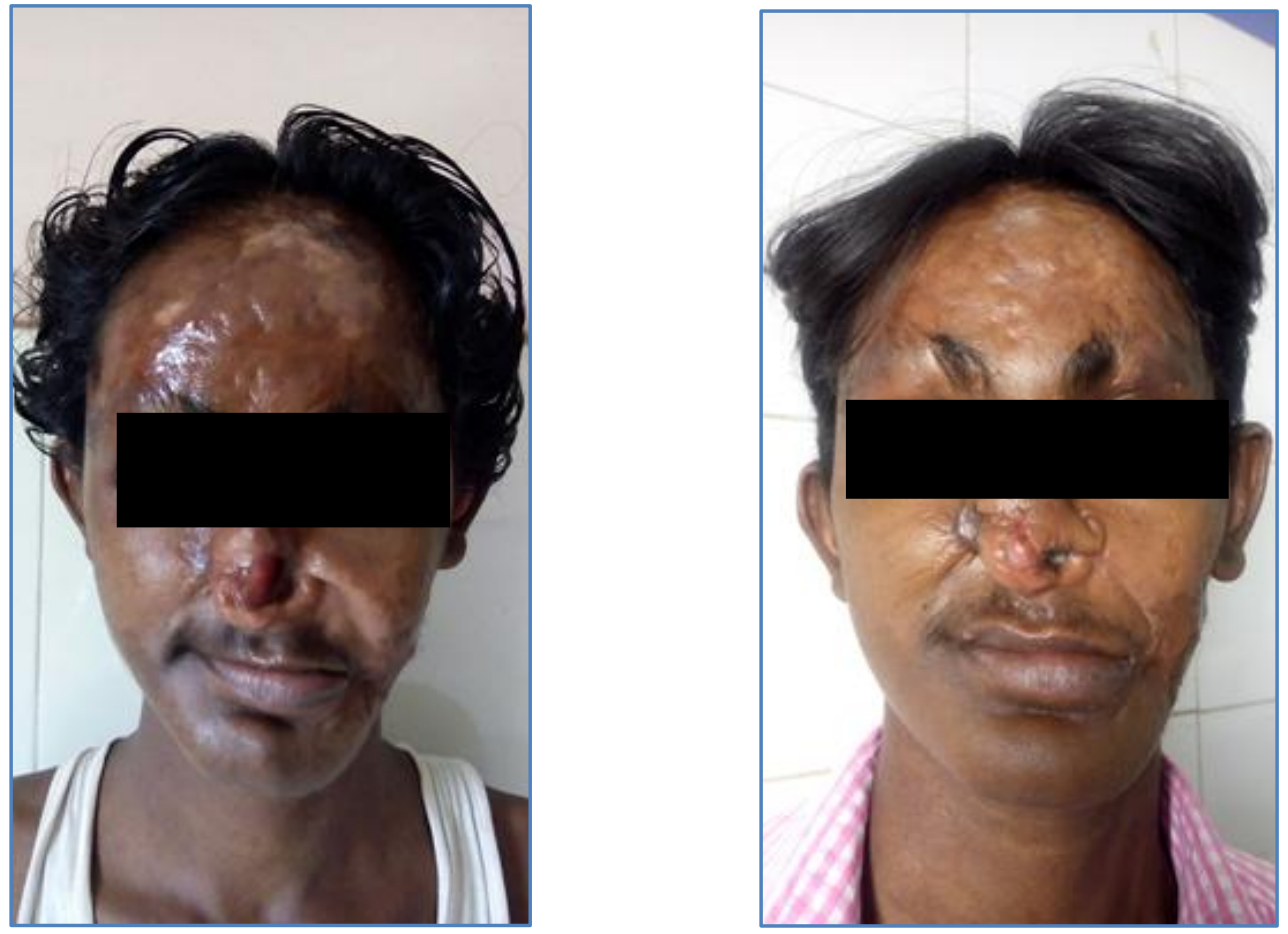

Plastic Surgical reconstruction of deformed nose before and after 


\section{AUTHORS:}

1. P. Guru Prasad

2. P. V. Sudhakar

3. R. Rama

4. P.V. S. V. P. H. S. Brahma

5. Padmasree Somala Y.

\section{PARTICULARS OF CONTRIBUTORS:}

1. Professor, Department of Dermatology, Andhra Medical College.

2. Professor and HOD, Department of Plastic Surgery, Andhra Medical College.

3. Assistant Professor, Department of Dermatology, Andhra Medical College.

4. Junior Resident, Department of Dermatology, Andhra Medical College.
5. Junior Resident, Department of Dermatology, Andhra Medical College.

\section{NAME ADDRESS EMAIL ID OF THE CORRESPONDING AUTHOR:}

Dr. P. Guru Prasad,

Professor,

Department of Dermatology,

AMC, Vizag.

E-mail: gppatnala@yahoo.co.in

Date of Submission: 29/12/2014.

Date of Peer Review: 30/12/2014.

Date of Acceptance: 06/01/2015.

Date of Publishing: 14/01/2015. 